\title{
Corrosion Monitoring Using Embedded Piezoelectric Sensors
}

\author{
Lei Qin ${ }^{1, *}$, Qi Qin ${ }^{1}$, Hongwei Ren ${ }^{2}$, Biqin Dong ${ }^{3}$ and Feng Xing ${ }^{3}$ \\ ${ }^{1}$ School of Civil Engineering and Architectural Engineering, University of Jinan, Jinan 250022, China \\ ${ }^{2}$ School of electrical engineering, University of Jinan, Jinan 250022, China \\ ${ }^{3}$ School of Civil Engineering, Guangdong Province Key Laboratory of Durability for Marine Civil Engineering, \\ Shenzhen University, Shenzhen 518060, China
}

\begin{abstract}
In this research, a new type of corrosion monitoring technique for reinforce concrete was developed. The technique used piezoelectric sensors to detect the ultrasonic signals during corrosion. The mechanism of the method was presented. Experiment was carried out to monitor the corrosion process using piezoelectric sensors. The corrosion was also monitored using stain gauge for comparison.
\end{abstract}

Keywords: Concrete, corrosion, piezoelectric sensor, steel bar, ultrasonic.

\section{INTRODUCTION}

Reinforced concrete structure is widely used in modern construction. However, reinforced concrete tends to suffer from serious environmental conditions and the durability is a severe problem. One of the main causes of durability in reinforced concrete structures is reinforcement corrosion. Therefore, the maintenance of structures for their safety requires effective monitoring techniques for assessing the reinforcement corrosion. researchers have developed a variety of relatively mature methods of nondestructive testing, such as acoustic emission, electrochemical techniques and so on [1-10].

Recently, health monitoring based on modern smart materials have been developed very quickly. Piezoelectric material is one type of smart material and used very widely [11-15]. The material could be used as sensors and actuators. In this research, a new type of sensor was developed to monitor the corrosion of steel bar. The sensor used piezoelectric material to generate and receive ultrasonic waves. The waves were guided by the steel bar and the corrosion of the steel bar could be detected.

\section{FABRECATION OF THE SENSOR}

The piezoelectric sensor included two piezoelectric ceramic elements which were used for generating and receiving ultrasonic waves and one steel bar was used as wave guider. The diameter of the piezoelectric ceramic element was $10 \mathrm{~mm}$ and the thick was $1 \mathrm{~mm}$. Coaxial cable

\footnotetext{
*Address correspondence to this author at the School of Civil Engineering and Architectural Engineering, University of Jinan, Jinan 250022, China; Tel: (+86)15069082207; Fax: (+86)82765943;

E-mail: cea_qin@ujn.edu.cn
}

was connected to the opposite electrodes of the piezoelectric ceramic element. Then, the piezoelectric ceramic was enclosed using epoxy. At last, the piezoelectric element was bonded onto the opposite surfaces of a steel bar of $100 \mathrm{~mm}$. The sensor is shown in Fig. (1).

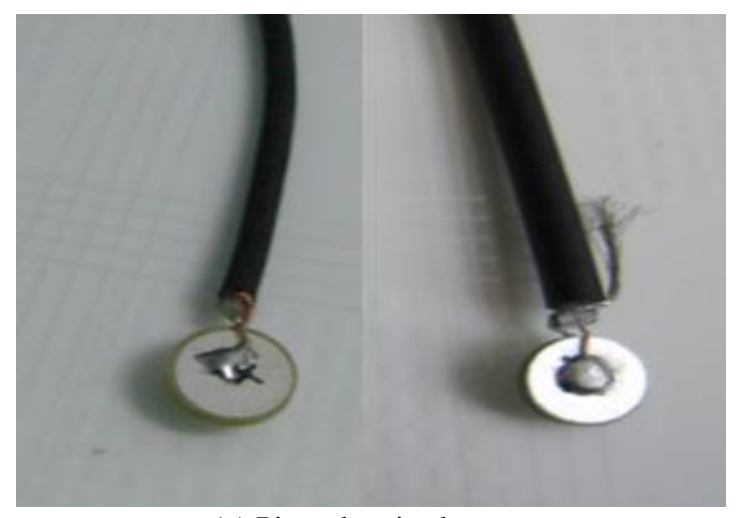

(a) Piezoelectric element

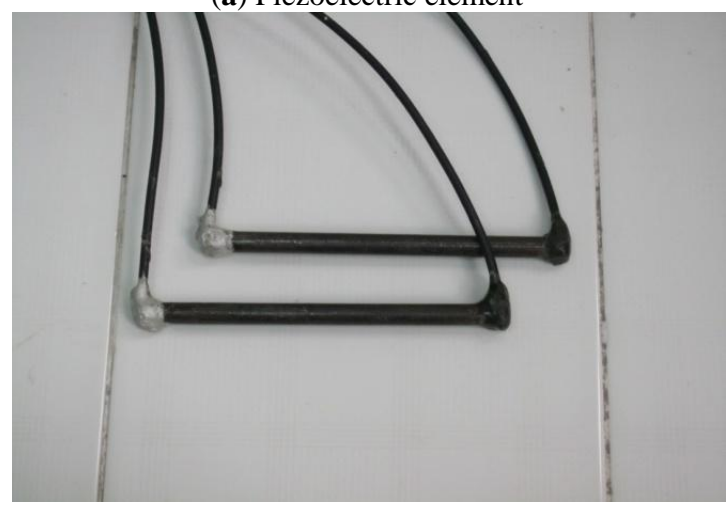

(b) Corrosion sensor

Fig. (1). Piezoelectric ceramic and the corrosion sensor. 


\section{THE MECHANISM OF THE CORROSION DETECTION METHOD}

As is known that the corrosion process is the accumulation of different types of oxidation products. The corroded part of a steel bar may induce increase of the volume because the corrosion products have different material properties. The steel bar was designed to guide the ultrasonic wave. When the sensor was embedded into concrete, part of the wave energy would transmit to the concrete. When the corrosion products were accumulated, less wave energy would emit to the concrete. Thus, during corrosion the wave amplitude would change. The working principle is shown in Fig. (2).

Before the corrosion sensor was embedded in concrete, the properties of the sensor were examined. One piezoelectric element was stimulated by an electric pulse from a signal generator (Agilent 33120A) and the other piezoelectric element was used to receive the ultrasonic wave, which was recorded by an oscilloscope (Tektronix TPS2024). The input electric pulse was a step function of $\pm 10 \mathrm{~V}$. The input electric pulse and the received wave are shown in Fig. (3). The sensor was then cast into a concrete beam with a cover thickness of $10 \mathrm{~mm}$. After one week curing, the operation was repeated. The received wave is shown in Fig. (4). After the sensor was embedded into concrete the wave amplitude decreased obviously. It could be seen that the sensor could response to the change of its surrounding state. Next, the sensor would be used to monitor the corrosion process.

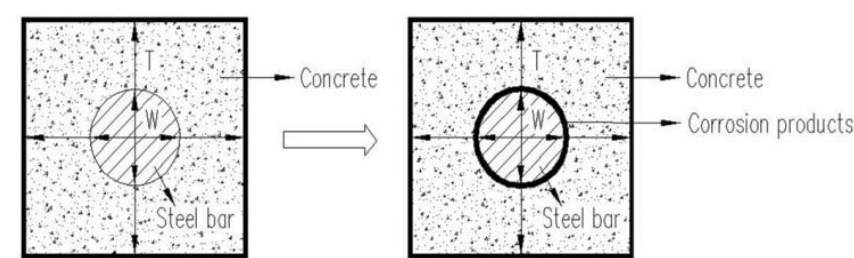

Fig. (2). Ultrasonic waves propagating in steel bar and concrete.

(W: wave propagating in steel bar; $\mathrm{T}$ : wave transmitted into concrete)

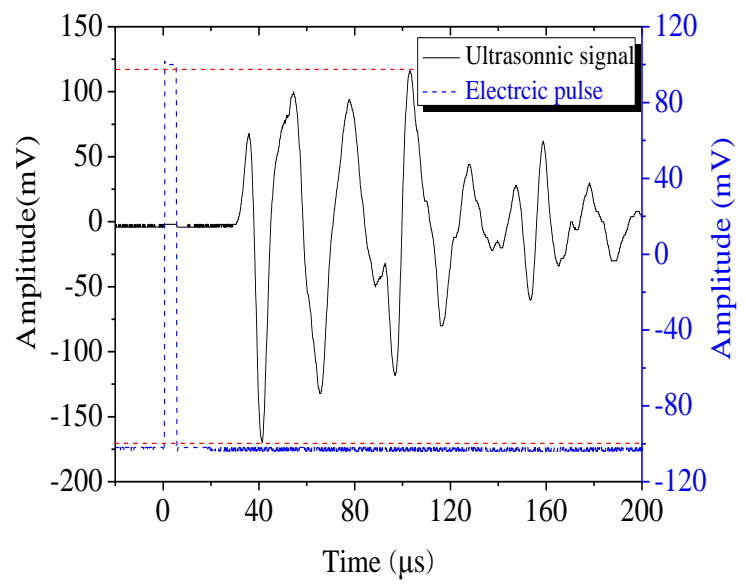

Fig. (3). Ultrasonic wave received before the sensor was embedded into concrete.

\section{CORRISION ACCELERATION TEST}

In order to accelerate corrosion process, the concrete specimen with embedded sensor was place in $3 \% \mathrm{NaCl}$ solution and the corrosion circuit was connected using the direct-current power. The embedded reinforcement bar in the specimen was connected to the anode of the direct-current power and the cooper rod was connected to the cathode of the direct-current power [16]. Both ends of steel bar were connected with signal generator and oscilloscope. Strain gauge was also bonded onto the surface of the concrete beam to measure the strain of the specimen. The instruments in the acceleration test are shown in Fig. (5). The potential used in the acceleration test was 2 volts. The ultrasonic wave signals were measured per hour. Measurement was stopped until the cracks appeared on the surface of concrete specimen.

The waves recorded at $10 \mathrm{~h}$ and $60 \mathrm{~h}$ are shown in Fig. (6). During corrosion the amplitude of the wave increased. The reason is interpreted in the above. The corrosion product layer decreased the transmitted wave energy. Thus, the amplitude increased.

The relation of time, wave amplitude and strain is shown in Fig. (7). During the early stage of the corrosion, the wave amplitude and the strain both increased linearly.

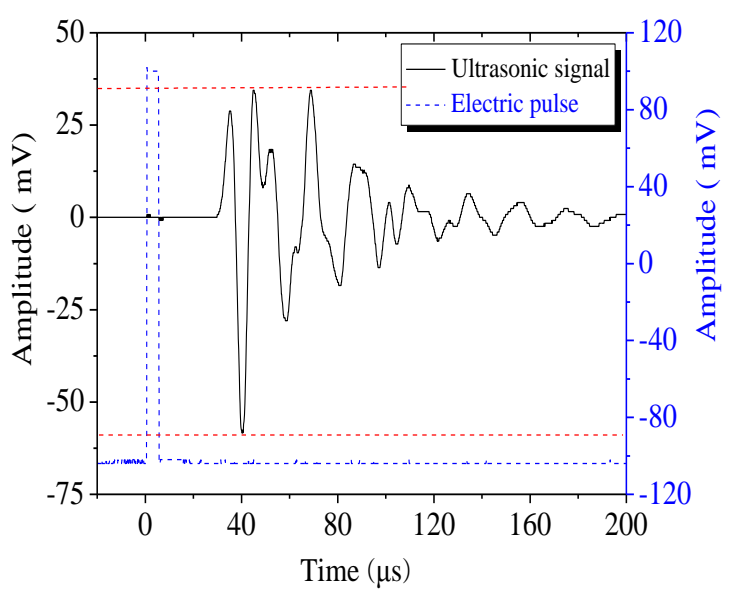

Fig. (4). Ultrasonic wave received after the sensor was embedded into concrete.

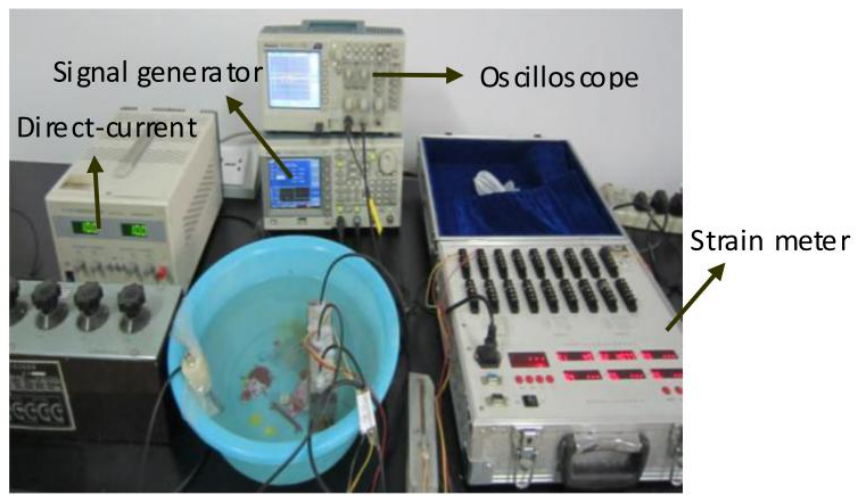

Fig. (5). Test instruments used in corrosion monitoring. 


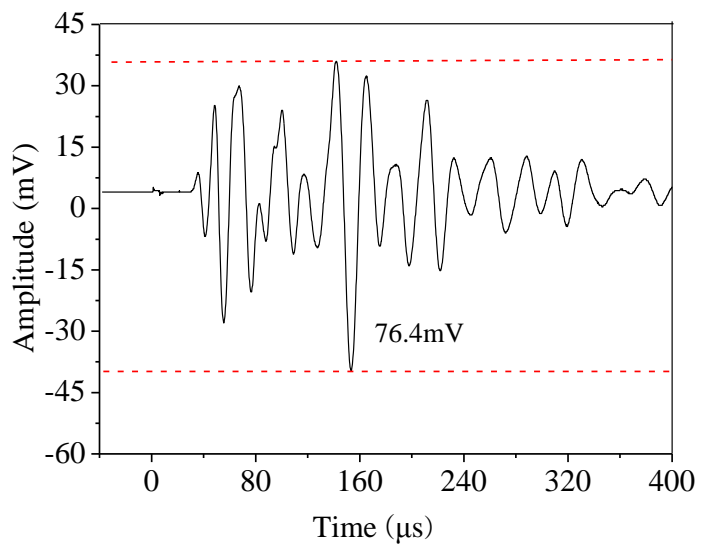

(a) Wave received at $10 \mathrm{~h}$

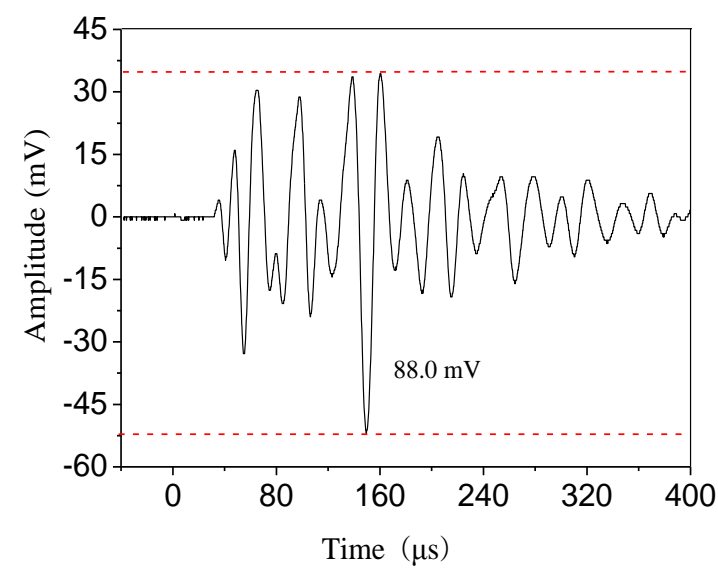

(b) Wave received at $60 \mathrm{~h}$

Fig. (6). Ultrasonic wave received in the test.

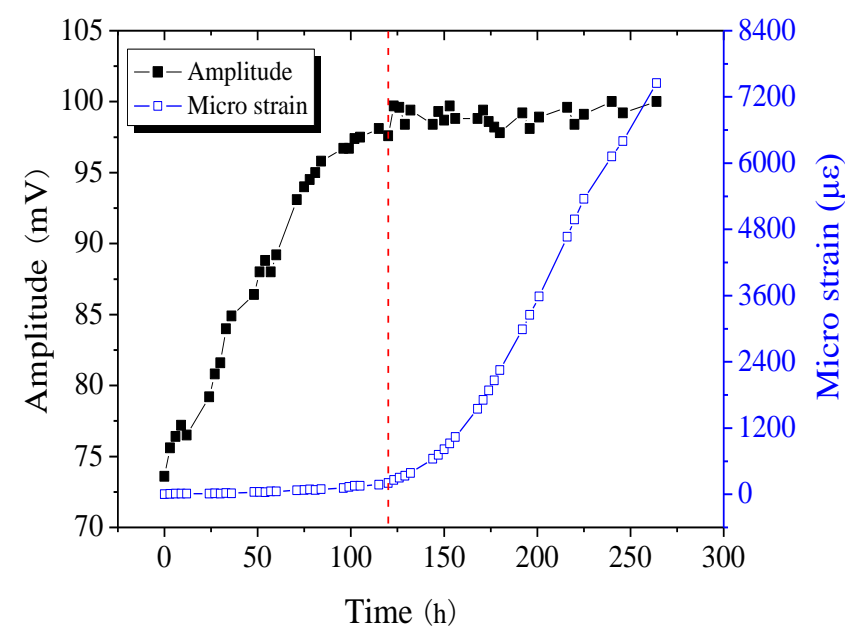

Fig. (7). Increase of amplitude and micro strain versus time.

At about $120 \mathrm{~h}$, the amplitude stopped increasing and the strain increasing rate became very large. We know that when the strain increased very quickly, it means that small cracks around the steel bar were induced due to the expansion the corrosion product. The cracks changed the way the wave propagation from steel bar to concrete.

Thus, the amplitude of the wave could detect the initiation of the corrosion and the cracking of the concrete. It should be noted that the experiments had very good repeatability.

\section{CONCLUSION}

In this paper, a new type of piezoelectric sensor is applied to corrosion monitoring. The novel piezoelectric sensor include two piezoelectric ceramic elements which are used for generating and receiving ultrasonic waves and one steel bar was used as wave guider. The accumulation of the corrosion products changed the wave transmission. Thus, the wave amplitude increased with the corrosion process. It is very important that the method could detect the cracking of the concrete around the steel bar.

\section{CONFLICT OF INTEREST}

The authors confirm that this article content has no conflicts of interest.

\section{ACKNOWLEDGEMENTS}

The financial support is from the National Natural Science Foundation of China (51378239) and National Key Basic Research Program by MOST (Project No.271 2011CB013600; Issue No: 2011CB013604).

\section{REFERENCES}

[1] R.J. Zhang, A. Castel and R. Francois. "Concrete cover cracking with reinforcement corrosion of $\mathrm{RC}$ beam during chloride- induced corrosion process," Cement. Concrete Res., vol.40, pp.415-425, 2010 .

[2] T. Parthiban, R. Ravi, and G.T. Parthiban. "Potential monitoring system for corrosion of steel in concrete," Adv. Eng. Software, vol.37, pp. 375-381, 2006.

[3] J.S. Reou and K.Y. Ann. "The distribution of hydration products at the steel-concrete interface for concretes subjected to electrochemical treatment," Corr. Sci., vol.52, pp.2197-2205, 2010.

[4] M. Ohtsu and Y. C. Tomoda. "Phenomenological model of corrosion process in reinforced concrete identified by acoustic emission," Mat.J., vol.105, pp.194-199, 2008.

[5] M. Pour-Ghaz, O.B. Isgor and P. Ghods. "The effect of temperature on the corrosion of steel in concrete," Corr. Sci., vol.51, pp.415425, 2009 .

[6] L.Q. Li, S.G. Dong and W. Wang. "Study on interaction between macro-cell and micro-cell in the early corrosion process of reinforcing steel in concrete," Technol. Sci.,vol.5, pp.1285-1289, 2010.

[7] S. Feliu, J.A. Gonzalezet and J.M. Miranda. "Possibilities and problems of in situ-techniques for measuring steel corrosion rates in large reinforced concrete structures," Corr. Sci., vol.47, pp.217238, 2005.

[8] B. Elsener. "Macrocell corrosion of steel in concrete-implications for corrosion monitoring, " Cement. Concrete Composites, vol.24, pp.65-72, 2002.

[9] R. Capozucca. "Damage to reinforced concrete due to reinforcement corrosion," Construct. Build. Mat., vol.5, pp.295303, 1995. 
[10] L. Bertolini, M. Carsana and P. Pedeferri. "Corrosion behaviour of steel in concrete in the presence of stray current," Corr. Sci.,vol.49, pp.1056-1068, 2007.

[11] B. Panagiotis and K.D. Dilip. "Composite piezoelectric sensors for smart composite structures, "Int. Sympo. on Electrets., vol.3, pp.731-734, 1999 .

[12] Z.J. Li and D. Zhang. "Cement-based smart material Cement matrix piezoelectric composites," Concr. Sci. Eng., vol.3, no.6, pp.116-120, 2001.

[13] B. Shen , X.M. Yang and Z.J. Li. "A cement based piezoelectric sensor for civil engineering structure," Mat. Struct, vol.39, no.1, pp. 33-37, 2006.
[14] K.K. Tseng and L.S. Wang. "Smart piezoelectric transducers for in situ health monitoring of concrete," Smart Mat. Struct., vol.13, no.5, pp.1017-1024,2004.

[15] V. Giurgiutiu and A.N. Zagrai. "Embedded self-sensing piezoelectric active sensors for online structural identification," J. Vbr. Acou., vol.124, no.1, pp.116-125, 2002 .

[16] B. H. Oh, K. H. Kim and B. S. Jang. "Critical corrosion amount to cause cracking of reinforced concrete structures, " Acid Mat. $J .$, vol.7, pp.333-339, 2009.

(C) Qin et al.; Licensee Bentham Open.

This is an open access article licensed under the terms of the Creative Commons Attribution Non-Commercial License (http://creativecommons.org/licenses/ by-nc/3.0/) which permits unrestricted, non-commercial use, distribution and reproduction in any medium, provided the work is properly cited. 